\title{
A FURTHER ANALYSIS OF VARIABILITY IN MANIOLA JURTINA L.
}

\author{
K. G. MoWHIRTER \\ Genetics Laboratory, University Museum, Oxford
}

Received 16. ii. 57

IN a series of papers on Maniola jurtina, the Meadow Brown Butterfly, Dowdeswell and Ford (1952-55) have shown that the distribution of spotting on the underside of the hind wings is a sensitive index of micro-evolutionary divergences. The numerical nature of the character scored, the tendency of the insect to form isolated communities, and its overall commonness, all contribute to making it a useful object for evolutionary studies.

\section{SPOT-DISTRIBUTION IN THE MALES}

Early results established a typical pattern of male spot-distribution with a mode at 2 spots. This pattern was found all over the mainland of England and in the Isles of Scilly. Deviations were found in the Isle of Man, where one population had nearly as many males at $I$ spot as at 2 spots, and in Ireland, where two populations were found to show an even greater divergence from the English pattern in that males with o and I spots were relatively much more frequent. Populations on two islands in the Scilly group, St Agnes' and Great Ganilly, were found to be deviating in the other direction ; that is, having an excess of males at 3 and 4 spots and a deficiency of males at $o$ and I spots, though in these cases the modes at 2 spots were always just maintained.

It was clear that male spot-distribution could vary, but was being held, presumably by selectional forces, in the familiar unimodal pattern over a large area.

Meanwhile, much more radical variations were found in female spot-distributions. Since these provided the foundation for the present studies of the effects of isolation on micro-evolution, and since time for field-work is often limited by the difficulties of arranging transport between the islands of Scilly, it has frequently been impossible to obtain adequate samples of males. Gradually, however, data on male spot-distributions have accumulated and it is now possible to offer certain generalisations about them.

(I) There is a highly significant correlation between the spotaverage in males and the spot-average in females of the same population. Spot-averages are obtained by adding all the spots and dividing by the number of insects. This procedure tends to blur the modalities of spot-distribution in the female but, owing to the prevalence of the 
unimodal male distributions, it serves to distinguish those male populations where $O$ and $I$ spot-frequencies are relatively high from those whose 3,4 and 5 spot-frequencies are high.

If male and female spot-averages for all years and all locations are plotted (excluding a few collections in which either females are fewer than 20 or males fewer than 25 ), we find an apparently linear arrangement, with the male mean at $2 \cdot$ I I spots, and maximum and minimum at respectively 2.73 and $I .22$ spots, and the female mean at $\mathrm{I} \cdot 02$ spots with maximum and minimum at respectively $\mathrm{I} \cdot 97$ and $0 \cdot 16$ (fig. I).

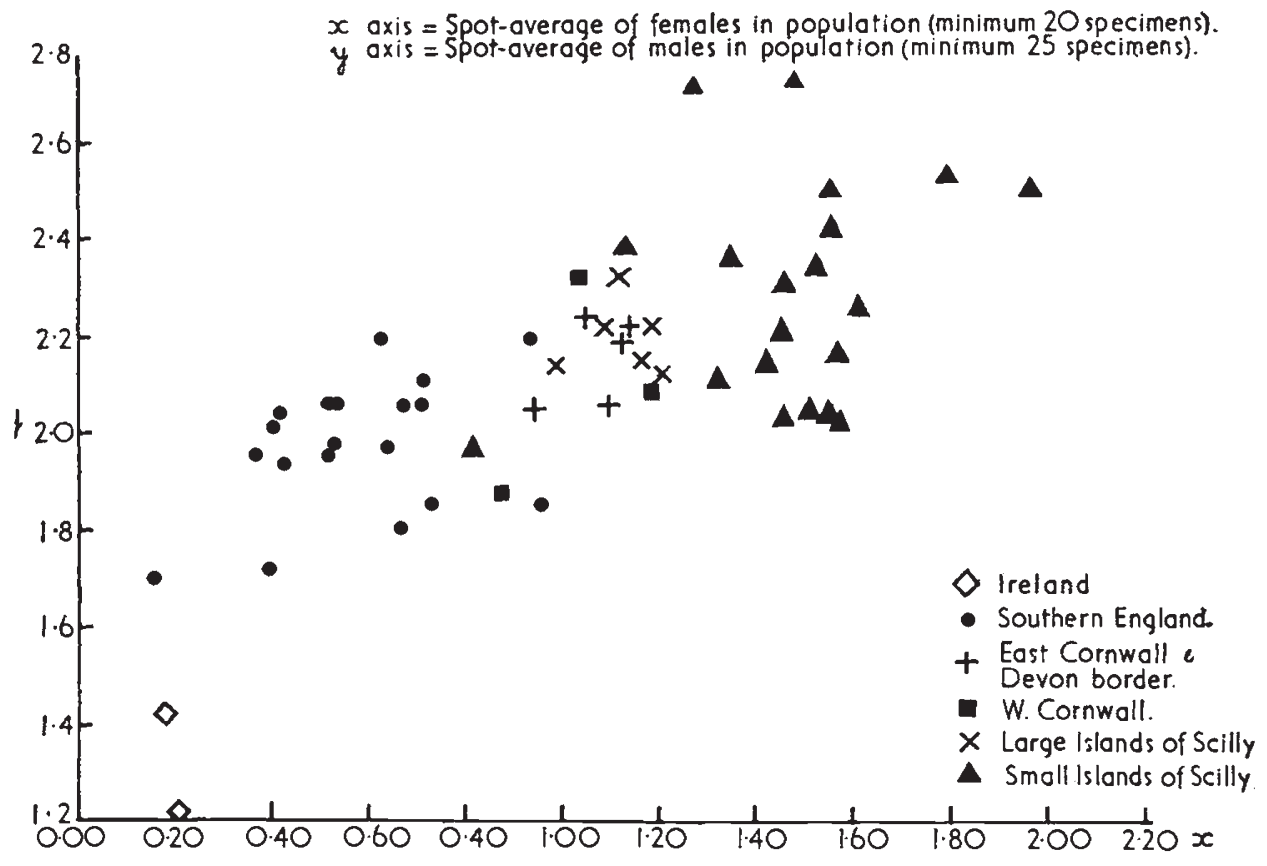

FIG. 1.-Correlation of male and female spot-averages in Maniola jurtina r $946-55$.

This arrangement of the data makes it quite clear that Ireland (and the Isle of Man) represents an area of low spot-average, and that most of the Scilly group represent an area of high spot-average. The mainland of England is intermediate, though resembling Ireland more than the extreme examples in Scilly. Again, the stabilised group of East Cornwall and West Devon is intermediate between the mainland of England and Scilly. We thus have a general cline in the direction of high spot-average from Ireland, through the Isle of Man, the mainland of Southern England, Cornwall, and the Isles of Scilly. Exceptionally, however, there is one group of populations in Scilly (see below, 2 (v)) which appears to maintain similar spotaverages to those of Southern England but, unfortunately, in most of these cases data of the male distributions are lacking.

On available data, the correlation coefficient may be crudely 
estımated at $0.7 \mathrm{I}$, which for 54 degrees of freedom is significant at the level of $0.00 \mathrm{I}$. (Two entries in fig. I happen to coincide.)

The simplest interpretation of this graph and the relationships it indicates is that some or all of the genetic factors which govern the amount of spotting in the insect, and which must be presumed also to influence other characters on which selection is operating, exert parallel influences in both males and females. While the mean of male spotting is consistently higher than that of female spotting, its variance is much less. Variability in the male, in other words, is "geared down". Hence, on first inspection, the male spot-distributions appear much less informative than the female ones. But they are, in fact, also an index of micro-ecological and micro-evolutionary processes.

(2) While female spot-distribution in Southern England has been examined by Dowdeswell and Ford (I953), who obtained samples from several points in the area Rugby-Ipswich-Canterbury-Taunton, and has been shown by them to be extremely homogeneous, at least up to the region of mid-Devon, it is a remarkable fact that male spot-distribution is much less homogeneous.

A study of table I illustrates this point. To avoid categories in which expectations are very small, and thus to make a $\chi^{2}$ test possible, it is necessary to accumulate the values for males at $o$ and I spots, and at 3,4 and 5 spots, and those for females at 2, 3, 4 and 5 spots. This gives two $3 \times 13$ tables and heterogeneity $\chi^{2}$ values for 24 degrees of freedom may be computed for the males and for the females of each sample. (One sample collected at Oxford in $195^{2}$ has been excluded because it contained only is males.) For the females, $\chi_{(24)}^{2}$ is 32.44 ; there is thus a probability value between 0.1 and 0.2 that the I 3 samples are homogeneous. Considering the varied climates of the places involved and the span of three years over which the samples were collected, this is indeed a sign of massive stability, especially when we reflect that the female spot-distributions are able, under certain conditions of isolation and perhaps other factors, to vary radically in Cornwall and the Isles of Scilly. Turning to the males, however, we find that $\chi_{(24)}^{2}$ is here $52 \cdot 68$, showing that this is a highly heterogeneous collection of samples, and that such variety could only be expected by chance in fewer than I in a rooo of such collections if they were from a homogeneous population. When we search these readings of male insects for possible causes of this variation, we find that there is a strong suggestion of an east-west cline. This is discussed under section (3) below.

The very few populations studied in Ireland and the Isle of Man suggest that an extreme of male variability may occur in this region, coupled with the general cline in the direction of spot-reduction. Again, in the South-West, in those isolated populations in the Scilly group where the trend is towards high spot-averages, the males may also be more variable than in Southern England. Nowhere, however, 
within the limits of our available data, do the male spot-distributions achieve the extraordinary homogeneity of the females in Southern England-a homogeneity which, as Dowdeswell and Ford (1952, 1953) point out, overrides very great differences in ecology.

(3) There are strong indications that a subsidiary cline exists in the males of the highly stabilised populations of Southern England. Readings from Lundy Island (off the North Devon coast) and from Oxford, Rugby and Taunton, suggest that these western populations, though conforming to the general picture of stabilisation, tend to have low spot-averages, while the readings from Canterbury and

TABLE I

Spot-distributions of South England samples 1950 to 1952, excluding Devon and Cornwall

\begin{tabular}{|c|c|c|c|c|c|c|c|c|c|c|c|c|c|c|}
\hline \multirow{2}{*}{ Spot numbers } & \multicolumn{6}{|c|}{ Male } & \multirow{2}{*}{ Total } & \multicolumn{6}{|c|}{ Female } & \multirow{2}{*}{ Total } \\
\hline & o & I & 2 & 3 & 4 & 5 & & 0 & I & 2 & 3 & 4 & $j$ & \\
\hline Rugby: 1950 & 3 & 8 & $3^{\mathrm{I}}$ & 7 & $\ldots$ & $\ldots$ & 49 & 26 & Io & 6 & I & 2 & $\ldots$ & 45 \\
\hline Canterbury $195^{\circ}$ & I & 4 & $3^{2}$ & II & I & I & 50 & 24 & I I & Io & 4 & I & $\ldots$ & 50 \\
\hline Ipswich I 950 & 3 & I5 & $6_{I}$ & 20 & 2 & I & 102 & 63 & $2 \mathrm{I}$ & 17 & 4 & $\ldots$ & 1 & 106 \\
\hline Taunton 1950 & 0 & 3 & 45 & 4 & I & $\ldots$ & 53 & 18 & 6 & 3 & I & $\ldots$ & $\ldots$ & 28 \\
\hline Salisbury I $95^{\circ}$ & I & 6 & 39 & I 3 & 2 & I & 62 & 26 & 8 & 8 & I & $\cdots$ & $\cdots$ & 43 \\
\hline Oxford $195^{\circ}$ & I & 7 & 36 & 4 & I & $\ldots$ & 49 & 37 & 12 & 4 & I & $\ldots$ & $\ldots$ & 54 \\
\hline Ipswich I95 I & I & 6 & $4^{I}$ & 7 & I & I & 57 & 70 & 22 & 9 & 5 & $\ldots$ & $\ldots$ & 106 \\
\hline Salisbury I95 I & 5 & II & $3^{2}$ & 5 & $\cdots$ & $\cdots$ & 53 & 22 & 2 & 1 & $\cdots$ & $\cdots$ & $\ldots$ & 25 \\
\hline Oxford I95I & I & 3 & 40 & 3 & $\ldots$ & $\therefore$ & 47 & 30 & Io & 3 & $\ldots$ & $\ldots$ & $\ldots$ & 43 \\
\hline Ipswich 1952 & 4 & 9 & 73 & I 3 & I & $\ldots$ & roo & $6 I$ & 22 & 16 & 4 & $\ldots$ & $\ldots$ & 103 \\
\hline Salisbury ${ }^{195^{2}}$ & 2 & 6 & 55 & 9 & 1 & $\ldots$ & 73 & $4^{I}$ & 8 & 6 & I & $\cdots$ & $\cdots$ & $5^{6}$ \\
\hline Winchester $195^{2}$ & 8 & 26 & 160 & 26 & 4 & I & 225 & 77 & 25 & I 2 & 3 & I & $\ldots$ & 118 \\
\hline Taunton I $95^{2}$ & 8 & 23 & $9^{\circ}$ & 8 & 3 & $\cdots$ & 132 & $2 \mathrm{I}$ & 15 & 7 & $\ldots$ & $\ldots$ & $\cdots$ & 43 \\
\hline Total. & $3^{8}$ & 127 & 735 & $13^{\circ}$ & 17 & 5 & 1052 & $5^{16}$ & 172 & 102 & 25 & 4 & I & 820 \\
\hline
\end{tabular}

Ipswich suggest a somewhat higher spot-average. Within the stabilised area, however, these differences are very slight and have not been very constant from year to year.

If such a cline in the male spot-distribution exists, we should expect to find that samples from each of the two sides of the whole area of Southern England, i.e. a western group and an eastern group, would be more homogeneous than both the groups taken together. We have seen in (2) above that the males across the whole of Southern England are in fact highly heterogeneous ; but if we select the five samples obtained at Rugby, Oxford and Taunton, we find that $\chi_{(8)}^{2}$ is only $14.90 ; \mathrm{P}$ then lies between 0.05 and $0 . \mathrm{I}$. This indicates some approach towards homogeneity. It will be observed, however, from table $I$ that there is considerable variation between years in the two pairs of samples from Taunton and Oxford. If we take the further step of accumulating the samples from Taunton and the samples from Oxford, adding also a sample taken at Oxford in 1952, which contained only fifteen males and which was, therefore, too small to stand on 
its own in a heterogeneity calculation, we find that $\chi_{(4)}^{2}=4.36$ and $P$ lies between 0.3 and 0.5 . (The Oxford sample of 1952 contained two males at o spot, two at I spot and eleven at 2 spots.) This indicates a very considerable degree of homogeneity.

Similarly, if we turn to the eastern wing of the Southern England populations and compare the samples taken at Canterbury and Ipswich, it is found that $\chi_{(6)}^{2}=6.91$, and that $P$ lies between 0.3 and 0.5 , again indicating considerable homogeneity. No substantial difference is made by accumulating the three Ipswich samples taken in the years $195^{\circ}$ to $195^{2}$, since $\chi_{(2)}^{2}=2 \cdot 22$, and the value for $P$ is hardly changed.

The question also arises whether a population sampled on Lundy Island in I 955 may legitimately be included with the Southern England collections, as suggested by its female spot-distribution. Forty-six males were taken and of these five had o spots, five had I spot, thirty-four had 2 spots and two had 3 spots. This sample seems to be tending in the direction of the Irish populations. Lundy lies in the Bristol Channel, twelves miles off the North Devon coast; its population of $M$. jurtina will, of course, be completely isolated from those of the English mainland. If the Lundy sample is included in a heterogeneity calculation with the populations of Rugby, Taunton and Oxford, $\chi_{(10)}^{2}=16.32$, and $\mathrm{P}$ lies between 0.05 and $0 \cdot 1$. If we aggregate the samples taken in different years at the same place and include the Lundy sample, $\chi_{(6)}^{2}=5.86$ and $\mathrm{P}$ lies between 0.3 and 0.5 . Thus we find that the inclusion of Lundy does not affect the homogeneity of the western group of South England samples. This is the first indication that the stabilisation found in South England may result from independent selectional adjustment of isolated populations as well as from gene-flow across the whole area.

The data of table $\mathrm{I}$ do not indicate any regularity in the variations from year to year which are so characteristic of the male samples from each location. Together with the west-east cline, however, they suffice to produce a heterogeneous male population alongside a strictly homogeneous female population. Nevertheless, there remains the general correlation between male and fenuale spot-averages ; it seems that within the area of stabilisation, male spotting reacts to some micro-evolutionary influence more readily than female spotting. Thus, while jurtina conforms to the rule of greater female variability over its whole range (Fisher and Ford, 1928), there can be a tendency towards greater male variability within the various stabilisation areas.

Clearly more extensive data are needed, not only from Southern England but also from its periphery, i.e. Wales, Northern England, Northern France and the Isle of Wight. If further data from Southern England establish this suggested cline, we should have a picture of extreme low spot-average in Ireland, and extreme high spot-average $(a)$ in the Scilly group and $(b)$ in East or South-East England. The cline in the direction of South-East England would be "damped", 
possibly through lack of isolation, and would express itself much more markedly in the males, while the cline in the direction of Scilly would be "damped" only as far as the critical Devon-Cornwall boundary, west of which isolation, and perhaps other ecological factors, permit wide variations which are here, however, chiefly expressed in the females.

\section{FEMALE SPOT-DISTRIBUTIONS IN THE ISLES OF SCILLY}

It is now becoming possible to discern certain patterns in the female spot-distributions.

A summary of the various types of female populations so far found might be useful.

(i) The large island group

On St Mary's, Tresco and St Martin's, the females are independently stabilised, showing roughly equal frequencies at $O, I$ and 2 spots; each provides about 30 per cent. of the total with a " tail " of about Io per cent., where the spots are 3,4 or 5 . The effect of plotting the distribution of these populations is to give a "flat-topped" curve. This stabilisation has been shown to be very strong, both from year to year and from island to island. Dowdeswell and Ford (1955) have attributed this to the need for a population covering an area of mixed ecology to achieve a compromise (and to equilibrate genefrequencies).

\section{(ii) Unimodal populations with a mode at 2}

These have been found on St Helen's, St Agnes', Samson South and Bryher (Gweal Hill). This last population and the population on St Helen's (in 1953, but not in I95 I) gave large readings for o-spot and I-spot. They thus tended to approach the "flat-topped" distribution of the large islands. (iii) Bimodal populations with a large mode at 2
and a lesser mode at 0

These have been found on Tean One, Tean Three, Arthur, Tresco Farm (in 1955), Samson North, and Old Man North.

(iv) Bimodal populations with a large mode at 0 and a lesser mode at 2

These have been found on St Martin's South-East and St Martin's North-West (two isolated areas of one of the "large" islands), and on Old Man South (though here with a high " tail ").

(v) Unimodal populations with a large mode at 0

These have been found on Bryher South, White Island, and on St Martin's opposite White Island. 


\section{(vi) Two unstable populations}

The population on Tean Five and that on Great Ganilly have moved between (ii), (iii) \& (iv) and (iii), \& (iv) respectively.

It will be seen that when spot-average is considered, (ii) and (iii) will tend to fall into a high spot-average group, and (iv) and (v) into a low spot-average group. (i) will be intermediate.

It is possible to plot these female spot-distributions in such a way as to make any "clumping" of separate populations detectable. The frequencies of $\mathrm{o}, \mathrm{I}$ and 2 spots are expressed as a percentage in each population (the "tail" being for the moment disregarded). The three values are then plotted on a triangular graph (fig. 2 ; and Appendix). When this is done, four main points are easily observed :

(a) The "small island" populations are divided sharply into two

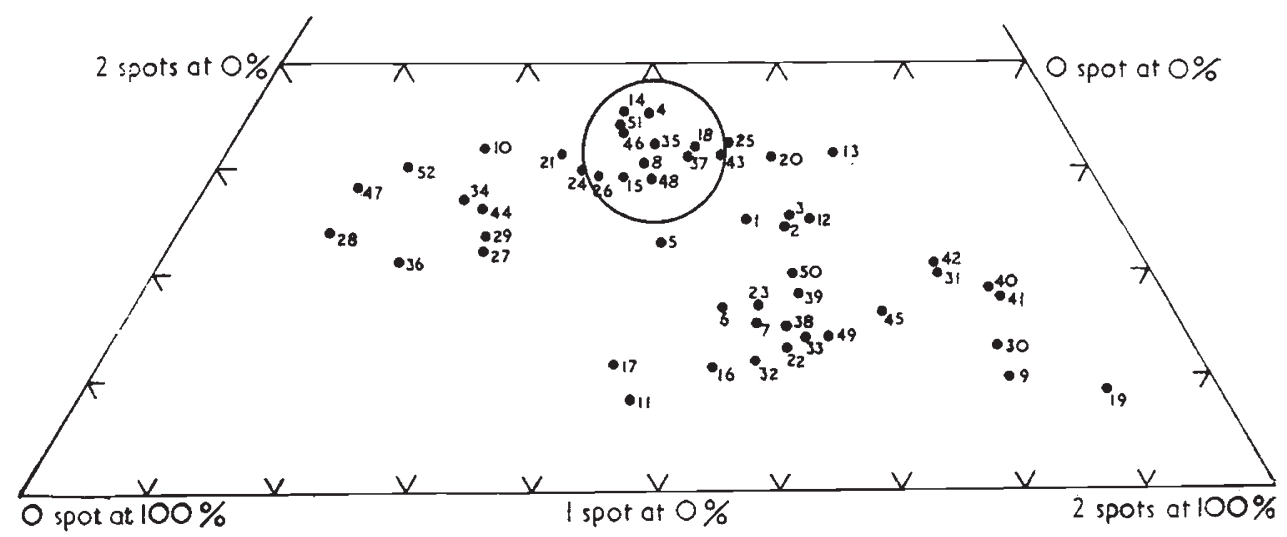

FIc. 2.-Maniola jurtina: Isles of Scilly-females I946-I955. Within all populations the number of specimens at I spot (expressed as a percentage of the total at no spot, I spot and 2 spots) never exceeds 35 per cent. All large is?and populations fall within the circle.

parts: (i) those with 2 spots below the 30 per cent. level, and (ii) those with 2 spots above the 39 per cent. level. There are no "small island" populations with 2 spots between 30 and 39 per cent.

(b) Into the gap fall the highly homogeneous populations of the large islands, which all have 2 spots between the 30 and 40 per cent. levels.

(c) No population has "one spot" in excess of 35 per cent., though very many approach this figure. (If mainland populations are added, this is even clearer: there is one exceptional and, on other grounds, inadmissible, population (Hayle, I95I) with I spot at 45 per cent. It is not certain that this sample was collected from onc locality; the 1952 sample (Dowdeswell and Ford, I953) was quite different). It appears that some populations are "pressed" against the $\mathrm{I}=35$ per cent. line. There must be some factor in the genetic control of spot-numbers which prevents the frequency of I-spot exceeding 35 per cent. of the total of the o-spot, I-spot and 
2-spot phenotypes. Nothing is, as yet, known about the individual genetics of spot-numbers since the insects have not been bred under laboratory conditions owing to the difficulty of mating them.

(d) "Tail" percentages (i.e. the proportion of 3-spot, 4-spot and 5 -spot specimens) vary more or less according to the 2-spot level.

It is clear that the female spot-distributions of the various populations in Scilly are not randomly scattered. Within the limitation that I-spot may not exceed 35 per cent., there is a clear tendency to "clump " into three groups, with a possibility of a fourth.

It is a reasonable first approximation to suggest that these groups reflect independent adjustments to at least three different types of ecology, possibly governed by the flora :

(a) Mixed-where, as on the large islands, a population has to compromise between various ecologies, and adopts the "flat-topped" distribution.

(b) Open-in the enclaves of St Martin's and on White Island (Old Man South, with a very high " tail ", may not really belong to this group). Here the trend is towards low spot-average and a mode at $o$.

(c) Luxuriant-in most, but not all, of the other islands where there is a high spot-average and the female distributions are unimodal at 2 or bimodal with a high mode at 2 .

This suggestion that the types of flora influence the specialisation of jurtina into high-spot and low-spot groups is necessarily very tentative, and will, of course, need confirmation from future observations. Exceptionally, the two isolated populations on Bryher do not conform to this pattern. The Gweal Hill habitat is more exposed than that of the southern part of the island, so that one would expect the spotdistribution patterns to be reversed. These two populations are, however, the only noticeable exceptions so far recorded to a possible generalisation that the spot-distributions tend to be adjusted to different types of ecology.

\section{SYNOPSIS OF AREAS}

Taking each area of the British Isles, on which data are available, in turn, one finds the following position :

\section{(i) Ireland and Isle of Man}

Lowest spot-averages in both sexes ( 0 about $\mathrm{x} \cdot 3$; $q$ about $0 \cdot 2$ ).

Probable high variability in males, tending to destroy the mode at 2.

Probable high stability in females; very large mode at $o$.

The only Isle of Man distribution so far obtained is intermediate between those of Ireland and those of South England (Dowdeswell and Ford, 1953). 


\section{(ii) South England}

Low spot-averages in both sexes ( 8 about $2 \cdot 0$; 9 about $0 \cdot 6$ ).

Moderate variability in males, but not disturbing the mode at 2.

Extremely high stability in females with a large mode at $o$.

\section{(iii) East Cornwall and Devon-Cornwall border}

There is an abrupt change in the course of a few miles (Dowdeswell and Ford, I953) to a series of populations which are stabilised on a different basis. These are characterised by medium spot-averages in both sexes ( $\delta$ about $2 \cdot 2$; $q$ about $I \cdot I)$.

Probable high stability in males with mode at 2 .

High stability in females with major mode at $o$, and minor mode at 2. Dowdeswell and Ford (I953) have shown that five samples of females from an area measuring $25 \times 20$ miles are homogeneous.

\section{(iv) West Cornwall}

M. jurtina appears to be much divided into isolated groups here so that the picture is rather similar to that of the Isles of Scilly, except that no "flat-topped" distributions have been found. Spot-averages are medium in both sexes ( 0 about $2 \cdot 1$; $ᄋ$ about $I \cdot 0$ ).

Not very many data on the stability of males are available, but the females show considerable variation.

\section{(v) Isles of Scilly}

There is a wide range of spot-averages here, though the general tendency is towards high counts; the highest counts ever recorded are in small islands of the group.

The spot-averages of the highly stabilised "large island " group are similar to those of East Cornwall ( $t$ about $2 \cdot 2$; $q$ about I.I), but the "flat-topped" female distribution with $0, I$ and 2 spots about equal, each at 30 per cent. of the whole, is characteristic of the group and found nowhere else.

Where the same isolated populations have been sampled in different years, they are usually highly stable, but extremely rapid shifts have been observed in Tean Five, where they were clearly associated with sudden ecological changes (Dowdeswell and Ford, 1955). The population on Great Ganilly has also changed between I95 I and I 955, but not so rapidly (Dowdeswell, Ford and McWhirter, I957). Here no obvious change in the ecology has been detected.

\section{DISCUSSION}

Many cases of sex-controlled polymorphisms are known in Lepidoptera ; examples of these are given by Ford (1945). It is clcar from this analysis of the spot-number variations of $M$. jurtina that the insect is equipped to adjust the stability of the phenotype ratios independently, or in both sexes. Yet while either sex may 
be stable or unstable, the overall correlation between the spot-averages in males and females always remains high. As the picture obtained of the spot-distributions in $M$. jurtina has expanded, so the extent of the insect's potential variability has become clearer. Three groups of populations showing highly stabilised female distributions and extending over habitats of varied ecologies have been found in Southern England, East Cornwall and the "large island" group of Scilly; each differs markedly from the others. Of these, at least the Scilly group is composed of rigorously isolated populations. All three groups must be presumed to retain the ability to vary their phenotype ratios, when selectional forces require it, but, except in the case of South English males, they have not been found doing so. In small populations, under the influence of isolation and consequent restriction of the variation in the ecology of the habitat, certain adjustments seem regularly to develop, so that the spot-frequencies are found to be altered.

A point of major theoretical interest arises when one asks the questions "Is variability in these isolated groups latent, or altogether lost?" and "Are modifying genes being worked out of the isolated populations, or does selection for success in a specialised habitat merely depress the level of some of them ?" Probably no population small enough to be affected by "genetic drift" has yet been studied. The indications, however, are that the consistent distributions arrived at independently by isolated populations, especially on Scilly, are due to selective influences. The rapid response of the population of Tean Five to observed ecological changes (Dowdeswell and Ford, I955) strongly suggests that selection can press an isolated population into a "corner" from which it will rebound when conditions are altered. There is no evidence that any modifiers have as yet been eliminated.

There is a striking parallel between the behaviour of $M$. jurtina with respect to spot-distribution in the British Isles and that of peripherally isolated populations in general, of which the Tanysiptera hydrocharis-galatea group of kingfishers in New Guinea, described by Mayr (I954), is an interesting example. In the case of the kingfishers differentiation has gone as far as speciation, while even subspeciation is rather doubtful in $M$. jurtina. Mayr finds that the central habitat of $T$. galatea, though covering enormous variations in climate, flora and fauna, contains a highly stabilised population, while the peripheral and isolated islands usually contain species which are highly differentiated, even from mainland species occupying areas of similar climatic conditions-a situation which has been described in many other animal species.

Mayr considers that both the "selectional " and "drift" theories are inadequate to explain the observed variations in Tanysiptera. He suggests that the chief influence on peripherally isolated populations is the revaluation of the selective advantages of genes in the new genetic environment that results from sudden isolation and intensive 
inbreeding of the "founder" genotypes. This precipitates the building up of a new gene complex in the isolated population.

It may be that $M$. jurtina is at the beginning of an evolutionary process which could lead to the condition described by Mayr in Tanysiptera. If variation in $M$.jurtina is an incipient micro-evolutionary process, we should expect external factors, e.g. selection based on ecological differences, to predominate; probably all but the very smallest groups of "founders" would contain all the alleles influencing spotting. In this way any colony likely to survive would adjust itself to its ecology after a few generations by using the same genctic potential. It is possible, however, to visualise a more advanced stage in such evolution after which sufficient incompatibility of genotypcs would have accumulated to make the composition of a "founder " population of prime importance. At this stage, certain further outside genes accruing to the new population would not simply be homogenised, causing a momentary disturbance of the gene-equilibrium; they would instead be confronted with a new genetic stabilisation and would be absorbed only rarely-subspeciation would then have begun.

At the present time, however, it seems likely that all populations of $M$. jurtina contain sufficient variability in respect of factors governing spot-numbers to establish whatever distribution is most advantageous, and that all these adjustments are being carried out against the same genetic background. The sudden change in Tean Five shows that all the genetic material required for coping with the ncw ecological situation was instantly available for selection, in a case where thc "founder" principle is inapplicable. Orving to the characteristics of M. jurtina and its habitats in Scilly, it is reasonable to hope that direct experimental tests will provide answers to some of these problems.

A further parallel between Mayr's observations and the present analysis is that the cline described in the $M$. jurtina males of South England occurs in a population whose females are highly stabilised. The populations sampled in South England are likely to be imperfectly isolated. Gene-flow is thus preventing even the beginnings of subspeciation. The continual operation of selection can do no more than produce a slight, but significant, cline in the males, which in its turn is but dimly reflected in the stable femalcs. Given isolation, however, as in West Cornwall and in the Isles of Scilly, the potential variability can be utilised and the first, though probably reversible, steps in the direction of subspeciation can be taken.

\section{SUMMARY}

I. A highly significant degree of correlation has been found between the average spot-number in males and in females of Maniola. jurtina all over the British Isles.

2. Though male spot-distributions generally vary less than females and always maintain a mode at 2 spots, they are highly heterogencous 
across Southern England in those places where females have been shown to be highly homogeneous.

3. Apparently the spot-distributions in each sex can be adjusted so that one sex may be comparatively labile and exhibit clines, while the other is highly stabilised.

4. The existence of a cline in both sexes from low spot-averages in Ireland, through the Isle of Man, Southern England, Cornwall, to high spot-averages on the Scilly group is established. A probable " damped" cline from low spot-average in western South England to a higher spot-average in eastern South England which is chiefly reflected in the males, is discussed.

5. It is established that female spot-distributions in isolated populations of the Scilly group tend to "clump" at certain patterns. They must have arrived at these independently under the influence of selectional forces.

6. A tentative identification of variations in the flora with the operative selectional force determining the pattern of female spotting is made.

7. M. jurtina behaves at its periphery as many animal species do, but the isolated populations do not appear to have as yet evolved inter-genotype incompatibility, at least so far as the factors governing spot-number are concerned. Experimental work on $M$. jurtina could provide further direct tests of the validity of various genetic theories of evolution.

Acknowledgments. - I am much indebted to Dr E. B. Ford, F.R.s., and to Mr W. H. Dowdeswell for valuable criticism and encouragement. Miss Christine Court of the Department of Human Anatomy, Oxford, kindly prepared the figures.

\section{REFERENCES}

DOWDESWELL, W. H., AND FORD, E. B. 1952. Heredity, 6, 99-109. DOWDESWell, W. H., AND FORD, E. B. 1953. Symposia Soc. Exp. Biol., 7, 254-273. DOWDESWELL, W. H., AND FORD, E. B. 1955. Heredity, 9, 265-272. DOWDESWELL, W. H., FORD, E. B., AND MCWHIRTER, K. G. 1957. Heredity, II, 51-65. FISHER, R. A., AND FORD, E. B. 1928. Trans. ent. Soc. Lond., 76, 367-384. FORD, E. B. 1945. Butterfies. Collins, pp. 231-240.

MAYR, E. 1954. In Evolution as a Process, pp. 157-180. Allen and Unwin. 


\section{APPENDIX}

Data from which fig. 2 is compiled

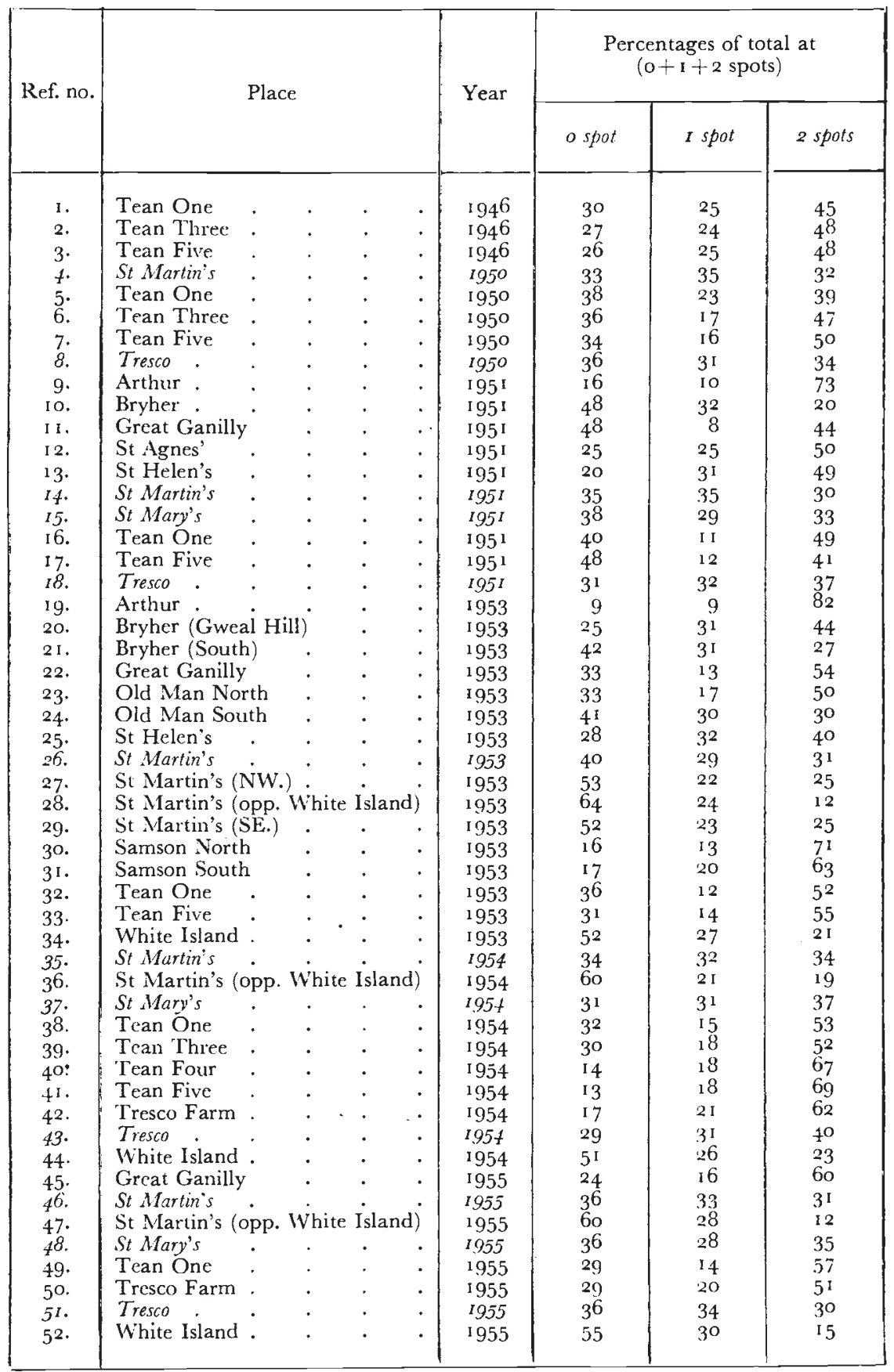

Places italicised are the main areas of the "large island group" ; these are all independently stabilised at the "flat-topped" distribution. All these samples, and these samples only, fall within the circle in fig. 2. 